\title{
Neutropenia management and granulocyte colony-stimulating factor use in patients with solid tumours receiving myelotoxic chemotherapy-findings from clinical practice
}

\author{
K. Krzemieniecki • P. Sevelda • F. Erdkamp • M. Smakal • M. Schwenkglenks • \\ J. Puertas • A. Trojan • Z. Szabo • K. Bendall • J. Maenpaa
}

Received: 21 May 2013 / Accepted: 8 October 2013 / Published online: 24 October 2013

(C) The Author(s) 2013. This article is published with open access at Springerlink.com

\begin{abstract}
Purpose Clinical practice adherence to current guidelines that recommend primary prophylaxis (PP) with granulocyte colonystimulating factors (G-CSFs) for patients at high ( $\geq 20 \%)$ overall risk of febrile neutropenia (FN) was evaluated.

Methods Adult patients with breast cancer, non-small cell lung cancer (NSCLC), small-cell lung cancer (SCLC), or ovarian cancer were enrolled if myelotoxic chemotherapy was planned, and they had an investigator-assessed overall FN risk $\geq 20 \%$. The primary outcome was FN incidence.

Results In total, 1,347 patients were analysed (breast cancer, $n=829$; NSCLC, $n=224$; SCLC, $n=137$; ovarian cancer, $n=157)$. Patients with breast cancer exhibited fewer individual FN risk factors than patients with other cancers and were far more likely to have received a high-FN-risk
\end{abstract}

Electronic supplementary material The online version of this article (doi:10.1007/s00520-013-2021-2) contains supplementary material, which is available to authorized users.

\section{K. Krzemieniecki $(\bowtie)$}

Oncology Department, University Hospital, Sniadeckich 10,

Krakow 31-531, Poland

e-mail: krzemieniecki@plusnet.pl

P. Sevelda

Department of Gynaecology, KH Hietzing, Vienna, Austria

\section{F. Erdkamp}

Department of Internal Medicine, Orbis Medisch Centrum, Sittard,

The Netherlands

M. Smakal

Ustav Onkologie a Pneumalogie Na Plesi, Nova Ves Pod Plesi,

Czech Republic

\section{Schwenkglenks}

Institute of Pharmaceutical Medicine, University of Basel, Basel,

Switzerland chemotherapy regimen. However, a substantial proportion of all patients (45-80\% across tumour types) did not receive G-CSF PP in alignment with investigator risk assessment and guideline recommendations. FN occurred in 127 patients overall (9\%, 95\% confidence interval (CI) 8-11\%), and incidence was higher in SCLC $(15 \%)$ than other tumour types ( $8 \%$ in ovarian and NSCLC, $9 \%$ in breast cancer). A post hoc analysis of G-CSF use indicated that G-CSF prophylaxis was not given within the recommended timeframe after chemotherapy (within 1-3 days) or was not continued across all cycles in $39 \%$ of patients.

Conclusions FN risk assessment was predominantly based on clinical judgement and individual risk factors, and guidelines regarding G-CSF PP for patients at high FN risk were not consistently followed. Improved education of physicians may

J. Puertas

Medical Oncology Service, Hospital Rio Hortega, Valladolid, Spain

A. Trojan

Onkozentrum, Klink Im Park, Zurich, Switzerland

Z. Szabo

Oncology Clinical Development, Amgen (Europe) GmbH, Zug, Switzerland

K. Bendall

Biostatistics, Amgen Ltd, Uxbridge, UK

J. Maenpaa

Medical School, University of Tampere, Tampere, Finland

J. Maenpaa

Department Obstetrics and Gynaecology, University Hospital, Tampere, Finland 
enable more fully informed neutropenia management in patients with solid tumours.

Keywords Chemotherapy $\cdot$ Myelotoxicity $\cdot$ Febrile neutropenia $\cdot$ Risk assessment $\cdot$ Granulocyte colony-stimulating factor $\cdot$ Prophylaxis

\section{Introduction}

Febrile neutropenia (FN) is a common side effect of myelotoxic chemotherapy and can result in dose reductions or delay to subsequent cycles of chemotherapy [1]. Reduced chemotherapy relative dose intensity (RDI) has been associated with poor outcomes in lymphoma and breast, lung and ovarian cancer [2-7]. FN frequently requires hospitalisation, which is associated with substantial use of medical resources and in-hospital mortality rates of up to $8 \%$ in patients with solid tumours [8-11].

Primary prophylaxis (PP) with granulocyte colonystimulating factors (G-CSFs; daily G-CSFs filgrastim and lenograstim, and once-per-cycle pegfilgrastim) reduces the incidence of $\mathrm{FN}$ and the duration of severe neutropenia $[12,13]$. Clinical guidelines recommend PP with G-CSFs for patients at high ( $\geq 20 \%$ ) overall FN risk [14-18]. Patients' overall risk should be assessed at the beginning of each chemotherapy cycle, using the risk associated with their planned regimen and individual risk factors such as older age and advanced disease. International guidelines also recommend G-CSF PP to maintain chemotherapy in settings where reduced RDI is associated with poor outcomes $[14,15]$.

IMPACT Solid was a large prospective observational study of routine clinical practice in Europe, Australia and Canada, designed to describe FN incidence and adherence to G-CSF guidelines in patients with solid tumours who had an overall physician-assessed $\mathrm{FN}$ risk of $\geq 20 \%$ (ClinicalTrials.gov: NCT00883181). An interim analysis of data from this study was presented in abstract form at the 2009 ECCO/ESMO meeting [19]. Additional post hoc analyses were performed to better understand the FN risk assessment and G-CSF use in the study.

\section{Material and methods}

Data regarding chemotherapy delivery, G-CSF use and haematological toxicities were recorded for each patient. Centres were selected to ensure data were recorded as part of routine clinical practice and to represent a variety of centres within each country. Eligible patients were enrolled sequentially. Upon completion of all planned chemotherapy cycles, or following cessation of chemotherapy for any reason, patients were followed up annually for 5 years or until disease progression or death. Long-term follow-up is ongoing; the current analysis reports neutropenia-related outcomes during the chemotherapy treatment period.

\section{Patients}

Patients aged $\geq 18$ years with breast, ovarian or lung cancer and receiving any cytotoxic chemotherapy were eligible if assessed by their physician to have an overall FN risk of $\geq 20 \%$. Prior radiotherapy was permitted if it had ceased $>2$ weeks before commencing chemotherapy in the current study. Where required, the study protocol was approved by institutional review boards and patients provided written informed consent.

\section{Outcome measures}

The primary outcome was the proportion of patients experiencing $\mathrm{FN}$ in cycles $1-8$, summarised by tumour type and overall G-CSF use. FN was defined as a single oral temperature $\geq 38.3{ }^{\circ} \mathrm{C}$, or a temperature of $\geq 38.0{ }^{\circ} \mathrm{C}$ for $\geq 1$ h with a neutrophil count of $<0.5 \times 10^{9} / \mathrm{L}$ or $<1.0 \times$ $10^{9} / \mathrm{L}$ and predicted to fall below $0.5 \times 10^{9} / \mathrm{L}$ [17] . Secondary outcomes included the proportion of patients experiencing FN in cycle 1, the G-CSF type and number of days' use, chemotherapy dose intensity and use of anti-infectives.

G-CSF use in the study was with either pegfilgrastim or with a daily G-CSF; patients were allowed to receive any daily G-CSF, and results for daily G-CSF were grouped together. The prespecified analysis of overall G-CSF use was derived programmatically, and patients were included in one of the following groups:

- Primary prophylaxis: G-CSF initiated within days 1-7 of chemotherapy cycle 1 if chemotherapy dosed for $\leq 7$ days or within days 1-11 if dosed for $>7$ days

- Secondary prophylaxis (SP): as above, with G-CSF initiated in cycle 2 or later

- Treatment: G-CSF initiated after day 7 in any cycle, or after day 11 if no subsequent prophylaxis

- No G-CSF : no G-CSF received as either prophylaxis or treatment

Note: Prophylactic G-CSF use in a single cycle was sufficient to meet the PP/SP definitions; there was no requirement for continued prophylaxis across all subsequent cycles. RDI was defined as dose intensity achieved by a patient relative to their planned dose intensity. 
Post hoc analyses

Received chemotherapy regimens were matched to a standard "textbook" regimen. Textbook regimens were assigned to a FN risk category (high $>20 \%$, moderate 10-20\%, low $<10 \%$ ) based on guidelines, published references of FN rates with specific regimens and author review (Supplemental Table 1). Patients who received a standard textbook regimen throughout the observation period remained in the respective chemotherapy FN risk category; patients were assigned to the "other" category if they received a regimen that could not be matched to a textbook regimen or if any agent in a textbook regimen was reduced by $>10 \%$ in cycle 1 or if the number of cycles differed from the standard regimen.

In a post hoc analysis of G-CSF use, a more stringent definition of prophylaxis was applied that more closely matched the labelling instructions for filgrastim and pegfilgrastim [20, 21]. Prophylactic use was defined as GCSF initiated within 1-3 days after completing chemotherapy within a cycle, and for the purposes of this report, we have termed this definition "on-schedule" prophylaxis to distinguish it from the prespecified analyses. G-CSF use initiated $\geq 1$ day after the FN event and within the same cycle was considered treatment/rescue use. For daily G-CSF, $\geq 3$ days of continuous administration was required to be considered on-schedule prophylaxis use.

Overall G-CSF use was analysed applying the more stringent definitions, and patients were included in one of the following groups:

- On-schedule PP: prophylactic G-CSF given in cycle 1 and all subsequent cycles

- Not on-schedule PP: all other use of G-CSF, including secondary prophylaxis, G-CSF given after day 3, or GCSF given as prophylaxis in at least one cycle but not in all cycles

- No G-CSF : no G-CSF at all given in any cycle (this is the same definition as the prespecified analysis)

Further analysis was conducted to characterize the G-CSF support given to patients who experienced an FN event using the more stringent "on-schedule" prophylaxis definitions.

In addition, whether patients who experienced $\mathrm{FN}$ received G-CSF prophylaxis in the next cycle was determined. $F N$ and no subsequent prophylaxis was defined as no on-schedule prophylactic G-CSF given in the next cycle after the first $\mathrm{FN}$, regardless of prior G-CSF support.

Statistical analysis

Sample size was chosen to allow adequate precision when estimating the proportion of patients achieving the primary outcome. The expected distribution across tumour types was: breast cancer, $n=839$; non-small cell lung cancer (NSCLC), $n=177$; small-cell lung cancer (SCLC), $n=78$ and ovarian cancer, $n=206$.

All analysis was descriptive in nature and was performed on the Full Analysis Set, which included patients who met the protocol-specified eligibility criteria and started $\geq 1$ chemotherapy cycle up to a maximum of 8 cycles. Analysis was performed using Statistical Analysis Software (SAS $\left.{ }^{\circledR}\right)$. Categorical data were summarised using the number and percentages of patients, with exact $95 \%$ confidence intervals (95\% confidence interval (CI)) where appropriate. Continuous data were summarised using means, standard deviations (SD), medians and interquartile ranges.

\section{Results}

Patient disposition

One thousand three hundred forty-seven of 1,370 enrolled patients (98\%) were included in the Full Analysis Set. Patients were treated between March 2007 and October 2009, at 85 centres in 11 European countries, 5 Canadian centres and 10 Australian centres. Centres were most commonly public (56 of $100,56 \%$ ) or university hospitals (25 of 100, $25 \%$ ). Patients were most frequently from Poland (21\%) and Australia or Italy (11\% each).

Over half the patients analysed had breast cancer $(n=829$, $62 \%$ ) (Fig. 1). Distribution of patients across the other tumour types was: NSCLC, $n=224$ (17\%); SCLC, $n=137(10 \%)$ and ovarian, $n=157(12 \%)$.

Among all patients, $79 \%(1,069$ of 1,347) completed all planned chemotherapy cycles; breast cancer patients had the highest proportion of chemotherapy completion (Fig. 1). The most common reasons for non-completion overall were disease progression (94 of 278, 34\%) and non-haematological adverse events (55 of 278, $20 \%$ ), with similar results across tumour types.

Patient demographics by tumour type

Breast cancer patients generally exhibited fewer individual FN risk factors than patients with other cancers (Table 1). Breast cancer patients tended to be younger, have better Eastern Cooperative Oncology Group (ECOG) performance status scores, be receiving first-line chemotherapy and have less advanced disease and fewer comorbidities than the other tumour types. SCLC patients were more likely to be female, have cardiovascular comorbidities, poorer ECOG scores and more advanced disease than NSCLC patients. 


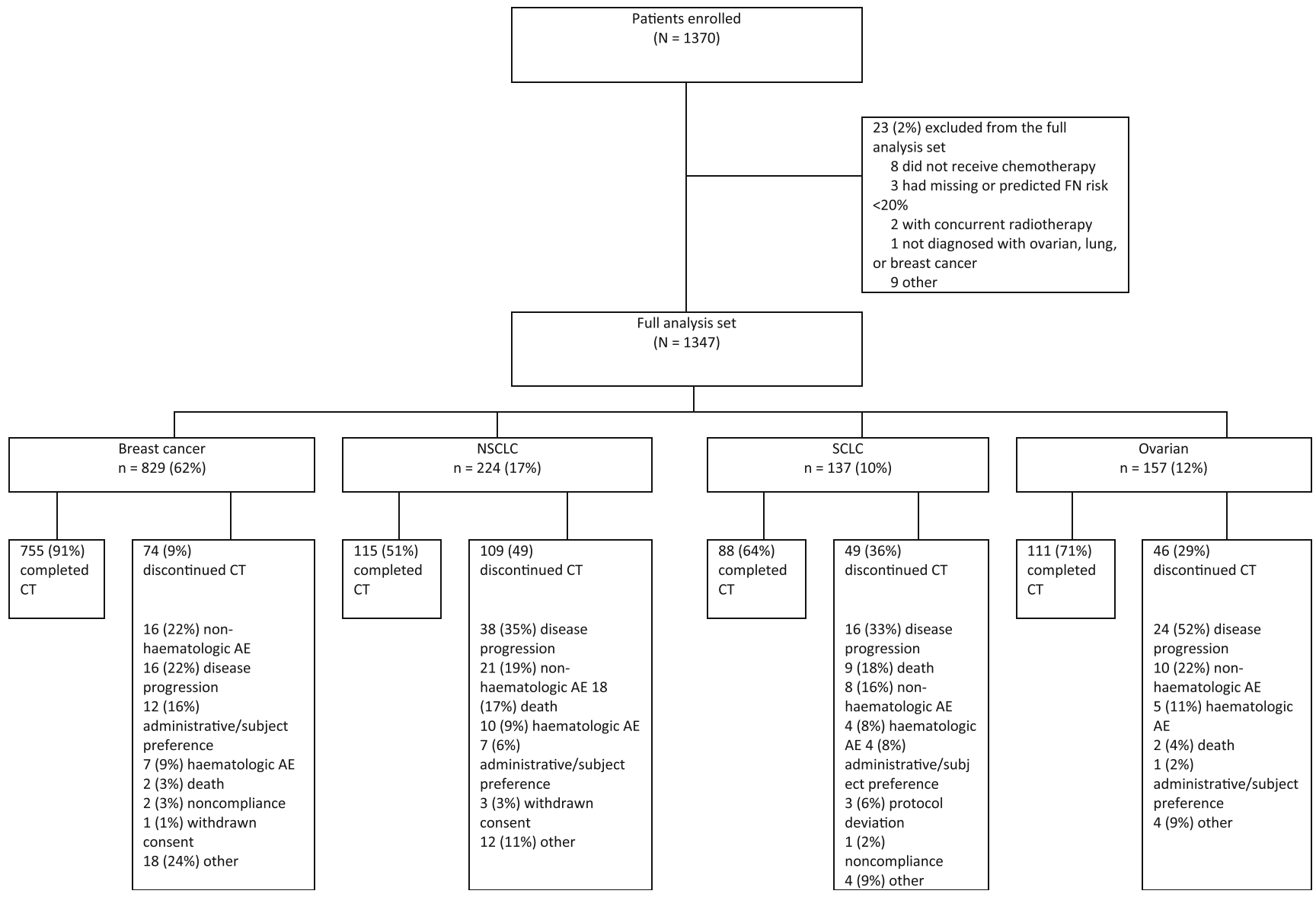

Fig. 1 Patient disposition. $C T$ chemotherapy

Patient demographics by tumour type and G-CSF use

Differences were observed in baseline characteristics between the overall G-CSF use groups (Table 2). Breast cancer patients receiving PP were less likely to have ongoing cardiovascular comorbidities, advanced disease and prior chemotherapy and/or radiotherapy than those not receiving PP. For the other tumour types, differences between G-CSF subgroups were less clear due to smaller patient numbers.

Received chemotherapy regimen and associated FN risk by tumour type

Breast cancer patients were substantially more likely than patients with other tumours to receive a high-FN-risk regimen
Table 1 Baseline demographics by tumour type

$C T$ chemotherapy, $R T$ radiotherapy

${ }^{\text {a }}$ Breast cancer and NSCLC, stage IV; SCLC, extensive; ovarian, stages III-IV

${ }^{\mathrm{b}}$ Derived from medical history records, percentages calculated from number of patients with any comorbidity

\begin{tabular}{lllll}
\hline & Breast $(N=829)$ & NSCLC $(N=224)$ & SCLC $(N=137)$ & Ovarian $(N=157)$ \\
\hline Age, mean \pm SD (years) & $53.1 \pm 10.9$ & $62.3 \pm 9.0$ & $62.1 \pm 8.8$ & $60.5 \pm 11.6$ \\
Age $\geq 65$ years, $n(\%)$ & $136(16)$ & $96(43)$ & $51(37)$ & $71(45)$ \\
Female, $n(\%)$ & $821(99)$ & $50(22)$ & $44(32)$ & $157(100)$ \\
ECOG 0-1, $n(\%)$ & $800(97)$ & $187(83)$ & $104(76)$ & $129(82)$ \\
Advanced stage ${ }^{\mathrm{a}}, n(\%)$ & $90(11)$ & $126(56)$ & $98(72)$ & $122(78)$ \\
Prior CT and/or RT, $n(\%)$ & $41(5)$ & $59(26)$ & $35(26)$ & $34(22)$ \\
Specific comorbidities ${ }^{\mathrm{b}}, n(\%)$ & & & \\
Any comorbidity & $247(30)$ & $121(54)$ & $73(53)$ & $70(45)$ \\
Cardiovascular & $101(41)$ & $64(53)$ & $44(60)$ & $37(53)$ \\
Respiratory & $24(10)$ & $47(39)$ & $27(37)$ & $5(7)$ \\
Hepatic/biliary & $7(3)$ & $2(2)$ & $3(4)$ & $3(4)$ \\
Renal & $4(2)$ & $4(3)$ & $2(3)$ & $5(7)$ \\
\hline
\end{tabular}


Table 2 Baseline demographics by tumour type by G-CSF PP use

\begin{tabular}{|c|c|c|c|c|c|c|c|c|}
\hline & \multicolumn{2}{|l|}{ Breast } & \multicolumn{2}{|l|}{ NSCLC } & \multicolumn{2}{|l|}{ SCLC } & \multicolumn{2}{|l|}{ Ovarian } \\
\hline & $\begin{array}{l}\text { PP } \\
(N=457)\end{array}$ & $\begin{array}{l}\text { No PP } \\
(N=372)\end{array}$ & $\begin{array}{l}\mathrm{PP} \\
(N=45)\end{array}$ & $\begin{array}{l}\text { No PP } \\
(N=179)\end{array}$ & $\begin{array}{l}\mathrm{PP} \\
(N=44)\end{array}$ & $\begin{array}{l}\text { No PP } \\
(N=93)\end{array}$ & $\begin{array}{l}\text { PP } \\
(N=31)\end{array}$ & $\begin{array}{l}\text { No PP } \\
(N=126)\end{array}$ \\
\hline Age, mean $\pm \mathrm{SD}$ (years) & $52.3 \pm 10.9$ & $54.2 \pm 10.9$ & $62.6 \pm 8.7$ & $62.3 \pm 9.1$ & $62.6 \pm 10.2$ & $61.9 \pm 8.0$ & $62.1 \pm 12.0$ & $60.1 \pm 11.5$ \\
\hline Age $\geq 65$ years, $n(\%)$ & $67(15)$ & $69(19)$ & $20(44)$ & $76(42)$ & $19(43)$ & $32(34)$ & $15(48)$ & $56(44)$ \\
\hline Female, $n(\%)$ & $453(99)$ & $368(99)$ & $13(29)$ & $37(21)$ & $12(27)$ & $32(34)$ & $31(100)$ & $126(100)$ \\
\hline ECOG $0-1, n(\%)$ & $447(98)$ & $353(95)$ & $33(73)$ & $154(86)$ & $35(80)$ & $69(74)$ & $28(90)$ & $101(80)$ \\
\hline Advanced stage disease ${ }^{\mathrm{a}}, n(\%)$ & $39(9)$ & $51(14)$ & $29(64)$ & $97(54)$ & $28(64)$ & $70(75)$ & $22(71)$ & $100(80)$ \\
\hline Prior CT and/or RT, $n(\%)$ & $15(3)$ & $26(7)$ & $10(22)$ & $49(27)$ & $11(25)$ & $24(26)$ & $9(29)$ & $25(20)$ \\
\hline \multicolumn{9}{|l|}{ Specific comorbidities ${ }^{\mathrm{b}}, n(\%)$} \\
\hline Cardiovascular & $45(10)$ & $56(15)$ & $10(22)$ & $46(26)$ & $14(32)$ & $24(26)$ & $4(13)$ & $36(29)$ \\
\hline Respiratory & $10(2)$ & $10(3)$ & $5(11)$ & $31(17)$ & $9(20)$ & $14(15)$ & $0(0)$ & $2(2)$ \\
\hline Hepatic/biliary & $2(<1)$ & $2(<1)$ & $0(0)$ & $0(0)$ & $1(2)$ & $0(0)$ & $0(0)$ & $2(2)$ \\
\hline Renal & $2(<1)$ & $0(0)$ & $0(0)$ & $3(2)$ & $0(0)$ & $0(0)$ & $0(0)$ & $4(3)$ \\
\hline \multicolumn{9}{|l|}{ Chemotherapy risk, $n(\%)$} \\
\hline$<10 \%$ & $25(5)$ & $66(18)$ & $5(11)$ & $25(14)$ & $0(0)$ & $1(1)$ & $7(23)$ & 47 (37) \\
\hline 10 to $<20 \%$ & $31(7)$ & $26(7)$ & $13(29)$ & $47(26)$ & $17(39)$ & $39(42)$ & $7(23)$ & $1(1)$ \\
\hline$\geq 20 \%$ & $246(54)$ & $136(37)$ & $0(0)$ & $0(0)$ & $2(5)$ & $4(4)$ & $0(0)$ & $0(0)$ \\
\hline Other/unknown & $155(34)$ & $144(39)$ & $27(60)$ & $107(60)$ & $25(57)$ & $49(53)$ & $17(55)$ & $78(62)$ \\
\hline
\end{tabular}

$C T$ chemotherapy, $R T$ radiotherapy

${ }^{a}$ Breast cancer and NSCLC, stage IV; SCLC, extensive; ovarian, stages III-IV

${ }^{\mathrm{b}}$ Derived from medical history records marked as current or continuing and with relevant system organ class

(Fig. 2). Although not all breast cancer patients who received a high-risk regimen were given G-CSF PP, the G-CSF PP group was more likely to receive a high-risk regimen than the no PP group (Table 2). Ovarian cancer patients were more likely than other tumour groups to receive a low-risk regimen. Many patients across all tumour types received a non-standard "other" regimen (Fig. 2).

In breast and SCLC, patients who did not receive a highFN-risk regimen were older than those who received a highrisk regimen: In breast cancer, the median age was 50 years in $>20 \%$ risk regimens, 51 years in 10-20\% risk regimens and 54 years in $<10 \%$ risk regimens; in SCLC, the corresponding median ages were 57,61 and 60 years, respectively. Additionally, patients who did not receive a high-FN-risk regimen had poorer ECOG performance scores: In breast cancer, an ECOG score $0-1$ was found in $98 \%$ of patients receiving $>20 \%$ risk regimens, $95 \%$ of patients receiving 10 $20 \%$ risk regimens and $92 \%$ of patients receiving $<10 \%$ risk regimens; in SCLC, the corresponding proportions were 100 , 77 and $0 \%$, respectively. No high-risk regimens were administered to NSCLC or ovarian cancer patients. Patients who received non-standard "other" chemotherapy for whom the FN risk could not be determined were older than those who received high-risk chemotherapy (median age 69 years in breast cancer and 64 years in SCLC) with variability in ECOG scores (score of 0-1 in $96 \%$ of breast cancer and $74 \%$ of SCLC patients).

\section{G-CSF use}

In the prespecified analysis of overall G-CSF use, less than half of the patients overall (43\%) received G-CSF PP (Table 3, prespecified analysis). G-CSF PP use was the highest in breast cancer patients (55\%), followed by SCLC patients (32\%), and the lowest in ovarian and NSCLC patients (both $20 \%$ ). Fewer breast cancer patients received no G-CSF at all (21\%) than patients with other tumour types. G-CSF SP use was approximately $20 \%$ in each tumour group, and few patients received G-CSF as treatment.

Pegfilgrastim was the most commonly prescribed G-CSF in patients given PP, administered to $49-86 \%$ of patients receiving $\mathrm{PP}$ in different tumour types and to $82 \%$ of PP patients overall. Daily G-CSF was given to $16 \%$ of patients who received PP, with a mean $( \pm \mathrm{SD})$ number of days of GCSF per cycle: breast, 4.88 (1.84); NSCLC, 3.95 (1.18); SCLC, 4.95 (1.31) and ovarian, 3.67 (1.63). In breast cancer, pegfilgrastim PP was maintained for a greater number of continuous cycles than daily G-CSF PP: Pegfilgrastim PP was maintained until the fourth cycle in $95 \%$ of patients and until the sixth cycle in $89 \%$ of patients; daily G-CSF 
Chemotherapy regimen $\mathrm{FN}$ risk: $\quad->/=20 \% \quad \square 10$ to $<20 \% \quad \square<10 \% \quad \square$ Other

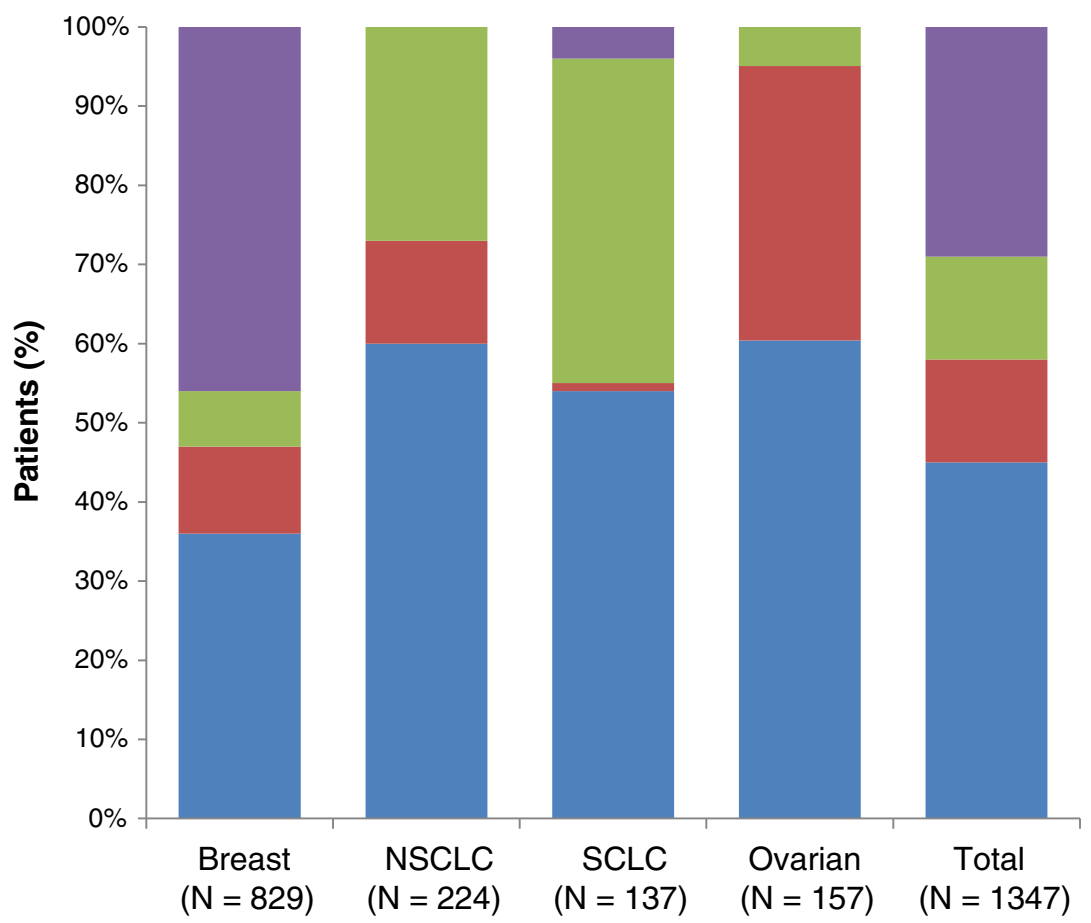

Fig. 2 Planned chemotherapy regimens and estimated FN risk. Chemotherapy FN risk assessment was determined by a post hoc clinical review of established guidelines and published literature. Data were not available for two patients (NSCLC and ovarian). FN risk could not be defined for regimens recorded as "other"; regimens which are not routinely used or variations to standard regimens and for which there were no published data regarding FN risk. Breast cancer, $>20 \% n=382$ (AC-Doc, ADoc, APac dd AC-Pac, DocAC(TAC), DocEC, EC-Doc, EDoc, FEC-Doc), 10-20 \% $n=57$ (Doc100, DocC, DocPLD, EPac, FEC 90), $<10 \% n=91$ (AC, AC-Pac, A-Pac, CarboPac, CMF, CycloPLD, EC, EC-Pac, FAC, FEC-Pac, Paclitaxel); NSCLC $>20 \%$

PP was maintained until the fourth cycle in $62 \%$ of patients and until the sixth cycle in $56 \%$ of patients.

In a post hoc analysis of overall G-CSF use, on-schedule G-CSF PP was more common in breast cancer patients than

$n=0,10-20 \% n=60$ (CarboDoc, CarboVin, CisDoc, CisEto [q3W], CisVin, Doc75), $<10 \% n=30$ (CarboGem, CarboPac, CisGem, CisPem, Gem, MIC); SCLC, $>20 \% n=6$ (CDE[ACE], Topotecan), 10-20\% $n=56$ (CarboDoc, CarboEto, CisEto[q4W], Doc75), $<10 \% n=1$ (CarboPac); ovarian, $>20 \% n=0,10-20 \% n=8$ (CarboDoc, Topotecan), $<10 \% n=54$ (CarboMono, CarboPac, CarboPLD, CisPac, Gem, Pac, PLD). Chemotherapy regimens: $A$ doxorubicin, Carbo carboplatin, $C i s$ cisplatin, $C$ cyclophosphamide, $d d$ dose-dense, Doc docetaxel, $E$ epirubicin, Etop etoposide, $F$ fluorouracil, Gem gemcitabine, $M$ methotrexate, $P a c$ paclitaxel, $P e m$ pemetrexed, $P L D$ pegylated liposomal doxorubicin, $T$ paclitaxel, Vin vinorelbine

other tumour types, and use of not on-schedule G-CSF PP was similar across tumour groups (Table 3, post hoc analysis). However, the proportion of patients who met the definition of on-schedule PP (29\% in total) was lower than the

Table 3 Overall G-CSF use by tumour type

\begin{tabular}{|c|c|c|c|c|c|}
\hline$n(\%)$ & Breast $(N=829)$ & $\operatorname{NSCLC}(N=224)$ & $\operatorname{SCLC}(N=137)$ & Ovarian $(N=157)$ & Total $(N=1,347)$ \\
\hline \multicolumn{6}{|c|}{ Prespecified analysis of G-CSF use } \\
\hline PP & $457(55)$ & $45(20)$ & $44(32)$ & $31(20)$ & $557(43)$ \\
\hline SP & $176(21)$ & $41(18)$ & $28(20)$ & $30(19)$ & $275(20)$ \\
\hline G-CSF treatment only & $21(3)$ & $18(8)$ & $9(7)$ & $14(9)$ & $62(5)$ \\
\hline No G-CSF & $175(21)$ & $120(54)$ & $56(41)$ & $82(52)$ & $433(32)$ \\
\hline \multicolumn{6}{|c|}{$\begin{array}{l}\text { Post hoc analysis based on the more stringent definitions of G-CSF prophylaxis and requirement for continued G-CSF prophylaxis in subsequent cycles } \\
\text { after first use }\end{array}$} \\
\hline On-schedule PP & $322(39)$ & $24(11)$ & $26(19)$ & $23(15)$ & $395(29)$ \\
\hline Not on-schedule PP & $332(40)$ & $80(36)$ & $55(40)$ & $52(33)$ & $519(39)$ \\
\hline No G-CSF & $175(21)$ & $120(54)$ & $56(41)$ & $82(52)$ & $433(32)$ \\
\hline
\end{tabular}


proportion who met the prespecified G-CSF PP definition (43\% in total) (compare Table 3, post hoc analysis with prespecified analysis).

\section{Neutropenia-related outcomes}

A higher proportion of breast cancer patients achieved $\geq 85 \%$ RDI ( $86 \%$ ) than did those with ovarian cancer (69\%), SCLC (66\%) or NSCLC (59\%). Systemic anti-infectives were used in the study by $39 \%$ of SCLC, $26 \%$ of breast cancer, $21 \%$ of NSCLC and $15 \%$ of ovarian cancer patients.

\section{Febrile neutropenia}

FN occurred in 127 patients overall $(9 \%, 95 \%$ CI 8, 11). Across all tumour types, FN incidence in all chemotherapy cycles ranged from 8 to $15 \%$. FN occurred in cycle 1 in 77 patients $(6 \%, 95 \% \mathrm{CI} 4,7)$, and for breast or lung cancer patients experiencing FN, their first FN episode occurred during cycle 1 in at least half of cases (Fig. 3a). FN incidence was higher among patients with SCLC than those with NSCLC. As described above, patient baseline characteristic and chemotherapy regimens differed between G-CSF use groups (using the prespecified definitions of G-CSF use). Patients who received G-CSF PP were at greater risk of $\mathrm{FN}$ - due to more individual risk factors and/or higher chemotherapy FN risk - than those who did not receive GCSF PP, meaning comparisons of FN incidence between these groups will be confounded. In patients receiving G-CSF PP, FN across all cycles was most common in SCLC (SCLC eight of $44,18 \%$; NSCLC four of $45,9 \%$; breast 42 of $457,9 \%$; ovarian zero of $31,0 \%$ ). In patients not receiving G-CSF PP, FN across all cycles was also more common in SCLC (SCLC 12 of $93,13 \%$; ovarian 12 of $126,10 \%$; breast 35 of 372 , $9 \%$; NSCLC 14 of $179,8 \%$ ).

Of the 127 patients who experienced FN, $35 \%$ were receiving on-schedule G-CSF in the cycle in which their first $\mathrm{FN}$ event occurred. The first FN event occurred in a cycle not supported with on-schedule G-CSF in a majority of patients across all tumour types (Fig. 3b). In addition, $39 \%$ of the 127 patients who experienced FN were not given on-schedule GCSF prophylaxis in the cycle after the first FN event occurred.

\section{Discussion}

The primary study objective was to describe FN incidence based on tumour type and G-CSF use, in patients with solid tumours receiving myelotoxic chemotherapy and assessed by their physician to be at high risk of FN. To fully understand the study outcomes, certain considerations related to the observational study design must be acknowledged. Physician discretion was used to determine overall FN risk at study

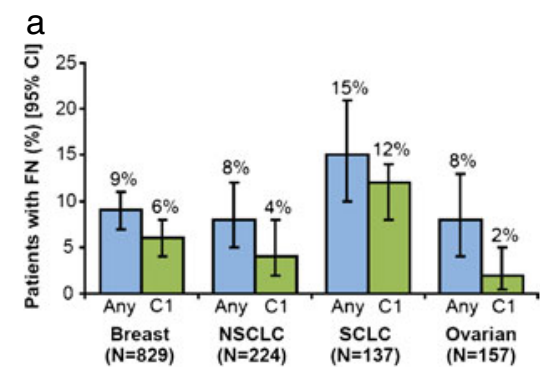

b

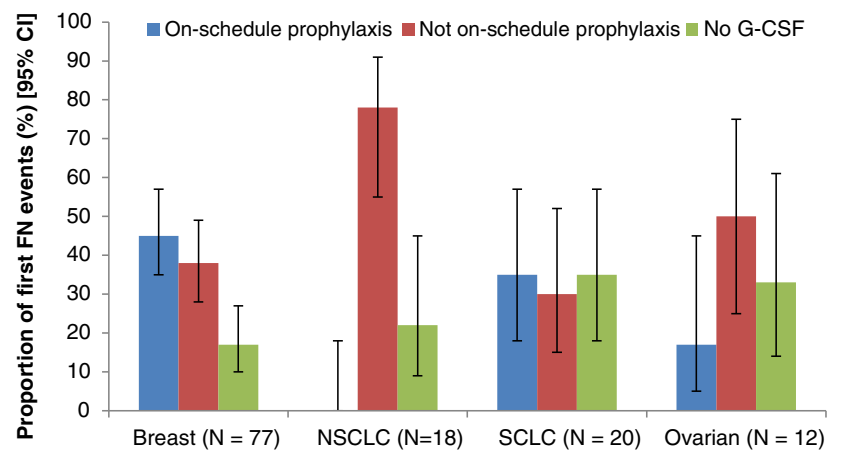

Fig. 3 Incidence of $\mathrm{FN}$ by tumour group. a Incidence of $\mathrm{FN}$ in cycles 1-8 and in cycle 1. Any Cycles 1-8; C1 cycle 1. b G-CSF use at the time of the first FN event, grouped according to the post hoc definitions of onschedule G-CSF use: On-schedule prophylaxis consists of patients who received on-schedule G-CSF in continuous cycles from the cycle in which it was first administered up to and including the cycle in which the first FN occurred. No G-CSF consists of patients who had received no G-CSF up to the time of FN. Not on-schedule G-CSF consists of the remaining patients - i.e., those who had received some G-CSF but did not receive on-schedule G-CSF in the cycle in which the first FN event occurred

entry, which may have led to overestimation of FN risk and the inclusion of patients for whom the true FN risk was $<20 \%$. In addition, patient selection led to differences in baseline characteristics between the PP and No PP G-CSF subgroups. This was most evident in breast cancer, where patients administered G-CSF PP were less likely to have patientrelated FN risk-factors and more likely to have received and completed a chemotherapy regimen associated with a high FN risk. These plus other differences between PP and no PP patients may confound comparisons of outcomes between G-CSF subgroups.

Nonetheless, the results of this large study of routine clinical practice provide important insights into FN risk assessment and subsequent neutropenia management. We observed notable differences in chemotherapy-related FN risk and individual FN risk-factors among patients assessed by physicians to be at high overall FN-risk. Breast cancer patients were relatively young with earlier-stage disease than patients with lung or ovarian cancer; they were more likely to complete their chemotherapy course and receive a standard regimen associated with a high FN-risk and at a RDI of $\geq 85 \%$. These findings suggest physicians placed greater emphasis on individual risk factors when assessing FN risk in patients with 
lung or ovarian cancer than those with breast cancer, where assessment of high FN risk was more likely to be driven by the choice of chemotherapy. The list of regimens included in guidelines is not exhaustive or conclusive [14-18], and the assignment of FN risk to a chemotherapy regimen was not possible in approximately $40 \%$ of cases (Fig. 2), due to the use of non-standard regimens or variations to standard regimens for which we were unable to find published data regarding the FN risk; this highlights the complexity faced by physicians when evaluating conflicting reports in the guidelines, published literature and expert opinion. Despite the study inclusion criteria, a regimen estimated to have an FN risk $\geq 20 \%$ was planned in, at most, one third of patients. Hence, individual risk factors were probably used to determine an FN risk $\geq 20 \%$ in a large number of patients. This provides further evidence that fully validated risk models are needed to improve risk assessment in patients receiving regimens for which the FN risk is $<20 \%$ or unknown [22-24]. The complexity of FN risk assessment may partly explain why patients with apparently low-risk regimens were enrolled in the study and why guidelines were not fully implemented such that not all patients received G-CSF PP, particularly those with lung and ovarian cancer.

Despite physician assessment of high overall FN risk, a substantial number of patients (45-80\%, Table 3, prespecified analysis) did not receive G-CSF PP as recommended by current guidelines [14-18]. Other studies of clinical practice have also reported poor guideline adherence in high-risk patients with NHL and solid tumours [25-28]. It is clear from the current and previously published studies that patients at greater risk of FN are more likely to be selected for G-CSF PP. Results from breast cancer patients in the current study showed that more than half of those given G-CSF PP received a high-FN-risk regimen, and they were younger with fewer comorbidities and less advanced disease than those not given G-CSF PP. This suggests that breast cancer patients selected for PP G-CSF were more likely to receive chemotherapy with curative intent, although treatment intent was not captured in the study. Few or none of the patients with other tumour types received a chemotherapy regimen associated with a high FN risk, and the differences in individual risk factors were quite variable between the G-CSF PP and no PP groups. These results suggest that individual risk factors carry less weight than the regimen risk when physicians decide whether to provide G-CSF PP.

Post hoc analyses were conducted to gain further insights into G-CSF prescribing patterns, using definitions of on-schedule prophylaxis that required administration within a therapeutically optimal window of 1-3 days after chemotherapy and for all subsequent cycles. This definition is more closely aligned with the approved product labelling instructions and guidelines [14-18, 20, 21]. Moreover, the on-schedule definition is supported by clinical evidence: The phase 3 registrational studies used the $\sim 24 \mathrm{~h}$ after chemotherapy schedule $[12,13]$ and a comparison of same-day versus next-day pegfilgrastim dosing in breast cancer and NHL patients suggested administration $24 \mathrm{~h}$ after chemotherapy provided better efficacy, although differences were not statistically significant [29]. Clinical data also supports G-CSF as prophylaxis given no later than 3 days after chemotherapy, with conflicting results as to whether 1 or 3 days after chemotherapy is superior [30, 31]. Although the FN risk is greatest in the first cycle, the risk continues in subsequent cycles [32], and patients should be supported equally in all cycles during which they are at high risk. Results of the prespecified analysis used clinical practicebased definitions of G-CSF prophylaxis; however, as might be expected with the narrower post hoc definitions, a smaller proportion of patients met the definition of receiving onschedule G-CSF PP. These findings indicate that current guidelines are not fully understood or implemented by all physicians and may indicate a related need for education. Several clinical studies have shown FN rates to be halved among patients with solid tumours and lymphomas [34, 35]. The current study supports these findings, with breast cancer patients more likely to receive myelosuppressive chemotherapy and GCSF PP than patients with lung or ovarian cancer, but experiencing similar or lower $\mathrm{FN}$ rates.

Compared with daily G-CSFs, pegfilgrastim PP has been shown to lower FN rates by approximately one third [35-37]. In the current study, pegfilgrastim was more commonly used for PP than daily G-CSF. Furthermore, in breast cancer, pegfilgrastim $\mathrm{PP}$ was maintained over a greater number of cycles than filgrastim. Across all tumour types, the number of days of daily G-CSF was lower than recommended, possibly due to the later chemotherapy lines received by patients with lung or ovarian cancer [14-18].

Results from the primary analysis show that patients from all tumour types were at risk of FN, and except for patients with ovarian cancer, the risk was the greatest in the first cycle as observed in other studies [13, 32, 33]. Furthermore, the highest incidence of FN occurred in SCLC (15\% overall and $12 \%$ in cycle 1 ) despite the relatively low use of high-risk regimens. Since less than one third of all SCLC patients were supported with G-CSF PP (and less than one fifth received onschedule PP), the need for increased awareness of FN risk appears particularly great in this population.

It was apparent that only a minority of patients (35\%) who experienced FN were receiving on-schedule G-CSF support at the time of their first $\mathrm{FN}$ event. In addition, a higher proportion of patients than anticipated (39\%) did not receive G-CSF prophylaxis in the cycle after the first FN occurred. An FN episode can have severe implications for both patients and healthcare systems: FN frequently results in hospitalization with in-hospital mortality rates of up to $10 \%$ reported [8]. Despite the potential impact of $\mathrm{FN}$, other than recommended administration or even complete lack of G-CSF was frequently observed in the 
study. Physicians may have selected other strategies for FN risk reduction such as using prophylactic antibiotics, shorter courses of daily G-CSF than recommended or modifying or reducing the intensity of the standard chemotherapy regimen. Antibiotic prophylaxis reduces the risk of infection and infection-related complications [38, 39]; it has no effect on the underlying neutropenia. In breast cancer patients undergoing TAC chemotherapy, antibiotics and shorter than recommended courses of daily G-CSF have both been shown to provide suboptimal protection against $\mathrm{FN}$, particularly in comparison to pegfilgrastim [37]. Overall, insufficient evidence is available to make a valid comparison between antibiotic prophylaxis and GCSF use [39]. Recent ASCO guidelines recommend that antibiotic prophylaxis should be limited to only those patients expected to experience long-lasting very severe neutropenia [40]. The potential for development of antibiotic resistance should be considered in clinical decision making. Reductions or changes to the chemotherapy regimen should be considered when treatment intent is palliative [15], but reductions in dose intensity may compromise long-term outcomes in patients receiving potentially curative chemotherapy [7]. This study indicates that improved education of physicians on all aspects of neutropenia management may enable more fully informed treatment decisions and improved outcomes in patients with cancer receiving myelotoxic chemotherapy.

Acknowledgments This work was funded by Amgen (Europe) GmbH. The authors would like to thank Claire Desborough and James O'Kelly, of Amgen Ltd, UK, who provided medical writing assistance. Florian Vogl, of Amgen (Europe) $\mathrm{GmbH}$ provided advice on post hoc chemotherapy FN risk classification. The authors would like to acknowledge the following investigators and sites who enrolled patients and contributed to the study: Beatriz Esteban, Hospital General de Segovia, Spain; Ana Fernandez Montes, Complexo Hospitalario de Ourense, Spain; Elisa Gallerani, Benvenuto Ferrari, Olivia Pagani, Istituto Ospedaliero MultiMedica di Castellanza, Varese, Italy; Prafull Ghatage, Tom Baker Cancer Centre, Canada; Richard Greil, Paracelsus Medical University, Salzburg, Austria; Jane Hill, Riverina Cancer Care Centre, Australia; Michael Hubalek, Medizinische Universitaet Innsbruck, Austria; Marek Jasiowka, Centrum Onkologii Instytut im. Marii Sklodowskiej-Curie, Krakowie, Poland; Ewa Kalinka-Warzocha, Wojewodzki Szpital Specjalistyczny Imienia Mikolaja Kopernika Regionalny Osrodek Onkologiczny, Poland; Dorothy Keefe, Royal Adelaide Hospital, Adelaide, Australia; Henrik Lindman, Uppsala University Hospital, Uppsala, Sweden; Olaf Loosveld, Amphia Ziekenhuis, Langendijk, the Netherlands; Juan Carlos Mellidez Barroso, Hospital Infante D. Pedro, Portugal; Francesco Nuzzo, Gaetano Bonfanti, Sandro Pignata , Istituto Nazionale Tumori "G. Pascale", Italy; Maria Cristina Pasquini, Ospedale Maggiore di Crema, Italy; Davide Pastorelli, Istituto Oncologico Veneto-IRCCS, Italy; Florentia Peintinger, Landeskrankenhaus Leoben, Austria; Robert Pirker, Medical University of Vienna, Vienna, Austria; Jan Pirnos, Hospital Ceske Budejovice, Czech Republic; Diane Provencher, Centre Hospitalier de L'Universite de Montreal Notre-Dame, Canada; Gary Richardson, Cabrini Hospital, Australia; Andre Robidoux, Centre Hospitalier Universite de MontrealHotel Dieu, Canada; Jan Ruit, Vlietland Ziekenhuis, the Netherlands; Mojmir Svabensky, Nemocnice Kyjov, Czech Republic; Nico van Walree, Amphia Ziekenhuis, Molengracht, the Netherlands; Ioannis Varthalitis,
General Hospital of Chania "Agios Georgios", Chania - Crete, Greece; Giacomo Vessia, City Hospital, Altamura, Italy.

Conflict of interest All authors were members of the IMPACT Solid study steering committee. K Krzemieniecki, P Sevelda, F Erdkamp, J Puertas and M Smakal have no other conflicts of interest. M Schwenkglenks has received research funding from Amgen (Europe) $\mathrm{GmbH}$ and has served on advisory boards for Amgen (Europe) GmbH. A Trojan has served on advisory boards for Amgen (Europe) GmbH. Z Szabo is an employee of Amgen (Europe) $\mathrm{GmbH}$ and holds shares in Amgen Inc. K Bendall was a consultant for Amgen (Europe) $\mathrm{GmbH}$ at the time of this study and is currently an employee of Amgen Ltd, UK. J Maenpaa has served on advisory boards for Amgen (Europe) $\mathrm{GmbH}$, MSD and Roche. The authors are fully responsible for content and editorial decisions for this paper. All authors had access to the primary study data. All authors reviewed the paper and approved the final version.

Open Access This article is distributed under the terms of the Creative Commons Attribution Noncommercial License which permits any noncommercial use, distribution, and reproduction in any medium, provided the original author(s) and the source are credited.

\section{References}

1. Pettengell R, Schwenkglenks M, Leonard R, Bosly A, Paridaens R, Constenla M, Szucs TD, Jackisch C (2008) Impact of Neutropenia in Chemotherapy-European Study Group (INC-EU). Neutropenia occurrence and predictors of reduced chemotherapy delivery: results from the INC-EU prospective observational European neutropenia study. Support Care Cancer 16:1299-1309

2. Pettengell R, Schwenkglenks M, Bosly A (2008) Association of reduced relative dose intensity and survival in lymphoma patients receiving CHOP-21 chemotherapy. Ann Hematol 87:429-430

3. Bosly A, Bron D, Van Hoof A, De Bock R, Berneman Z, Ferrant A, Kaufman L, Dauwe M, Verhoef G (2008) Achievement of optimal average relative dose intensity and correlation with survival in diffuse large B-cell lymphoma patients treated with CHOP. Ann Hematol 87: 277-283

4. Chirivella I, Bermejo B, Insa A, Pérez-Fidalgo A, Magro A, Rosello S, García-Garre E, Martín P, Bosch A, Lluch A (2009) Optimal delivery of anthracycline-based chemotherapy in the adjuvant setting improves outcome of breast cancer patients. Breast Cancer Res Treat 114:479-484

5. Radosavljevic D, Golubicic I, Gavrilovic D, Kezic I, Jelic S (2009) Do the time to chemotherapy response and the dose intensity have an impact on patient outcome in advanced non-small cell lung cancer? $\mathrm{J}$ BUON 14:203-209

6. Sarosy GA, Hussain MM, Seiden MV, Fuller AF, Nikrui N, Goodman A, Minasian L, Reed E, Steinberg SM, Kohn EC (2010) Ten-year follow-up of a phase 2 study of dose-intense paclitaxel with cisplatin and cyclophosphamide as initial therapy for poor-prognosis, advanced-stage epithelial ovarian cancer. Cancer 116:1476-1484

7. Wildiers H, Reiser M (2011) Relative dose intensity of chemotherapy and its impact on outcomes in patients with early breast cancer or aggressive lymphoma. Crit Rev Oncol Hematol 77:221-240

8. Kuderer NM, Dale DC, Crawford J, Cosler LE, Lyman GH (2006) Mortality, morbidity, and cost associated with febrile neutropenia in adult cancer patients. Cancer 106:2258-2266

9. Liou SY, Stephens JM, Carpiuc KT, Feng W, Botteman MF, Hay JW (2007) Economic burden of haematological adverse effects in cancer patients: a systematic review. Clin Drug Investig 27:381-396

10. Mayordomo JI, Lopez A, Vinolas N, Castellanos J, Pernas S, Domingo Alonso J, Frau A, Layola M, Antonio Gasquet J, Sánchez J, ENIA Study Group (2009) Retrospective cost analysis 
of management of febrile neutropenia in cancer patients in Spain. Curr Med Res Opin 25:2533-2542

11. Lathia N, Mittmann N, DeAngelis C, Knowles S, Cheung M, Piliotis E, Shear N, Walker S (2010) Evaluation of direct medical costs of hospitalization for febrile neutropenia. Cancer 116:742-748

12. Crawford J, Ozer H, Stoller R, Johnson D, Lyman G, Tabbara I, Kris M, Grous J, Picozzi V, Rausch G et al (1991) Reduction by granulocyte colony-stimulating factor of fever and neutropenia induced by chemotherapy in patients with small-cell lung cancer. $\mathrm{N}$ Engl J Med 325:164-170

13. Vogel CL, Wojtukiewicz MZ, Carroll RR, Tjulandin SA, BarajasFigueroa LJ, Wiens BL, Neumann TA, Schwartzberg LS (2005) First and subsequent cycle use of pegfilgrastim prevents febrile neutropenia in patients with breast cancer: a multicenter, doubleblind, placebo-controlled phase III study. J Clin Oncol 23:1178-1184

14. Smith TJ, Khatcheressian J, Lyman GH, Ozer H, Armitage JO, Balducci L, Bennett CL, Cantor SB, Crawford J, Cross SJ, Demetri G, Desch CE, Pizzo PA, Schiffer CA, Schwartzberg L, Somerfield MR, Somlo G, Wade JC, Wade JL, Winn RJ, Wozniak AJ, Wolff AC (2006) 2006 update of recommendations for the use of white blood cell growth factors: an evidence-based clinical practice guideline. $\mathrm{J}$ Clin Oncol 24:3187-3205

15. Aapro MS, Bohlius J, Cameron DA, Dal Lago L, Donnelly JP, Kearney N, Lyman GH, Pettengell R, Tjan-Heijnen VC, Walewski J, Weber DC, Zielinski C (2011) European Organisation for Research and Treatment of Cancer. 2010 update of EORTC guidelines for the use of granulocyte-colony stimulating factor to reduce the incidence of chemotherapy-induced febrile neutropenia in adult patients with lymphoproliferative disorders and solid tumours. Eur J Cancer 47:8-32

16. Crawford J, Caserta C, Roila F (2010) Hematopoietic growth factors: ESMO Clinical Practice Guidelines for the applications. Ann Oncol 21(5):248-251

17. Aapro MS, Cameron DA, Pettengell R, Bohlius J, Crawford J, Ellis M, Kearney N, Lyman GH, Tjan-Heijnen VC, Walewski J, Weber DC, Zielinski C, European Organisation for Research and Treatment of Cancer (EORTC) Granulocyte Colony-Stimulating Factor (GCSF) Guidelines Working Party (2006) EORTC guidelines for the use of granulocyte-colony stimulating factor to reduce the incidence of chemotherapy-induced febrile neutropenia in adult patients with lymphomas and solid tumours. Eur J Cancer 42:2433-2453

18. Crawford J, Allen J, Armitage J, Blayney DW, Cataland SR, Heaney ML, Htoy S, Hudock S, Kloth DD, Kuter DJ, Lyman GH, McMahon B, Steensma DP, Vadhan-Raj S, Westervelt P, Westmoreland M, National Comprehensive Cancer Network (2011) Myeloid growth factors. J Natl Compr Canc Netw 9:914-932

19. Krzemieniecki K, Erdkamp F, Lindman H, Maenpaa J, Puertas J, Schwenkglenks M, Sevelda P, Smakal M, Varthalitis I, Verma S (2009) G-CSF use and neutropenic events in patients with breast and lung tumours: data from routine clinical practice (IMPACT Solid study). Eur J Cancer Suppl 7:186

20. Neulasta ${ }^{\circledR}$ Summary of Product Characteristics. Amgen Europe B.V. http://www.ema.europa.eu/docs/en GB/document library/EPAR Product_Information/human/000420/WC500025945.pdf. Accessed July 2013

21. Neupogen ${ }^{\circledR}$ Summary of Product Characteristics. Amgen Europe B.V. http://www.mhra.gov.uk/home/groups/spcpil/documents/ spcpil/con1372737898391.pdf. Accessed July 2013

22. Jenkins P, Freeman S (2009) Pretreatment haematological laboratory values predict for excessive myelosuppression in patients receiving adjuvant FEC chemotherapy for breast cancer. Ann Oncol 20:34-40

23. Schwenkglenks M, Pettengell R, Jackisch C, Paridaens R, Constenla M, Bosly A, Szucs TD, Leonard R (2010) Risk factors for chemotherapy-induced neutropenia occurrence in breast cancer patients: data from the INC-EU Prospective Observational European Neutropenia Study. Support Care Cancer 19:483-490
24. Dranitsaris G, Rayson D, Vincent M, Chang J, Gelmon K, Sandor D, Reardon G (2008) Identifying patients at high risk for neutropenic complications during chemotherapy for metastatic breast cancer with doxorubicin or pegylated liposomal doxorubicin: the development of a prediction model. Am J Clin Oncol 31:369-374

25. Salar A, Haioun C, Rossi FG, Duehrsen U, Pettengell R, Johnsen HE, Jaeger U, Verhoef G, Schwenkglenks M, Bacon P, Bendall K, Lugtenburg PJ (2012) The need for improved neutropenia risk assessment in DLBCL patients receiving R-CHOP-21: findings from clinical practice. Leuk Res 36:548-553

26. Gerlier L, Lamotte M, Awada A, Bosly A, Bries G, Cocquyt V, Focan C, Henry S, Lalami Y, Machiels JP, Mebis J, Straetmans N, Verhoeven D, Somers L (2010) The use of chemotherapy regimens carrying a moderate or high risk of febrile neutropenia and the corresponding management of febrile neutropenia: an expert survey in breast cancer and non-Hodgkin's lymphoma. BMC Cancer 10:642-652

27. Steffens C-C, Eschenburg H, Kurbacher C, Goehler T, Schmidt M, Eustermann H, Schaffrik M, Otremba B (2012) Febrile neutropenia (FN) risk assessment and granulocyte colony-stimulating factor (GCSF) guideline adherence in patients with breast cancer-results from a German prospective multicentre observational study (PROTECT). Cancer Res 72:1-15-02, 24 Suppl, abstract

28. Potosky AL, Malin JL, Kim B et al (2011) Use of colony-stimulating factors with chemotherapy: opportunities for cost savings and improved outcomes. J Natl Cancer Inst 103:979-982

29. Burris HA, Belani CP, Kaufman PA, Gordon AN, Schwartzberg LS, Paroly WS, Shahin S, Dreiling L, Saven A (2010) Pegfilgrastim on the same day versus next day of chemotherapy in patients with breast cancer, non-small-cell lung cancer, ovarian cancer, and nonHodgkin's lymphoma: results of four multicenter, double-blind, randomized phase II studies. J Oncol Pract 6:133-140

30. Zwick C, Hartmann F, Zeynalova S, Pöschel V, Nickenig C, Reiser M, Lengfelder E, Peter N, Schlimok G, Schubert J, Schmitz N, Loeffler M, Pfreundschuh M, German High-Grade Non-Hodgkin Lymphoma Study Group (2011) Randomized comparison of pegfilgrastim day 4 versus day 2 for the prevention of chemotherapy-induced leukocytopenia. Ann Oncol 22:1872-1877

31. Loibl S, Mueller V, von Minckwitz G, Conrad B, Koehne CH, Kremers S, Forstbauer H, Linder M, Nekljudova V, Moebus V, GBG/AGO/NOGGO study groups (2011) Comparison of pegfilgrastim on day 2 vs. day 4 as primary prophylaxis of intense dose-dense chemotherapy in patients with node-positive primary breast cancer within the prospective, multi-center GAIN study: (GBG 33). Supp Care Cancer 19:1789-1795

32. Lyman GH, Morrison VA, Dale DC, Crawford J, Delgado DJ, Fridman M, OPPS Working Group, ANC Study Group (2003) Risk of febrile neutropenia among patients with intermediate-grade nonHodgkin's lymphoma receiving CHOP chemotherapy. Leuk Lymphoma 44:2069-2076

33. Lyman GH, Kuderer NM, Crawford J, Wolff DA, Culakova E, Poniewierski MS, Dale DC (2011) Predicting individual risk of neutropenic complications in patients receiving cancer chemotherapy. Cancer 117:1917-1927

34. Balducci L, Al-Halawani H, Charu V, Tam J, Shahin S, Dreiling L, Ershler WB (2007) Elderly cancer patients receiving chemotherapy benefit from first-cycle pegfilgrastim. Oncologist 12:1416-1424

35. Hershman D, Hurley D, Wong M, Morrison VA, Malin JL (2009) Impact of primary prophylaxis on febrile neutropenia within community practices in the US. J Med Econ 12:203-210

36. Cooper KL, Madan J, Whyte S, Stevenson MD, Akehurst RL (2011) Granulocyte colony-stimulating factors for febrile neutropenia prophylaxis following chemotherapy: systematic review and metaanalysis. BMC Cancer 11:404-410

37. von Minckwitz G, Kummel S, du Bois A, Eiermann W, Eidtmann H, Gerber B, Hilfrich J, Huober J, Costa SD, Jackisch C, Grasshoff ST, Vescia S, Skacel T, Loibl S, Mehta KM, Kaufmann M, German 
Breast Group (2008) Pegfilgrastim $+/$ - ciprofloxacin for primary prophylaxis with TAC (docetaxel/doxorubicin/cyclophosphamide) chemotherapy for breast cancer. Results from the GEPARTRIO study. Ann Oncol 19:292-298

38. Gafter-Gvili A, Fraser A, Paul M, Leibovici L (2005) Meta-analysis: antibiotic prophylaxis reduces mortality in neutropenic patients. Ann Intern Med 142:979-995

39. Herbst C, Naumann F, Kruse EB, Monsef I, Bohlius J, Schulz H, Engert A (2009) Prophylactic antibiotics or G-CSF for the prevention of infections and improvement of survival in cancer patients undergoing chemotherapy. Cochrane Database Syst Rev, CD007107

40. Flowers CR, Seidenfeld J, Bow EJ, Karten C, Gleason C, Hawley DK, Kuderer NM, Langston AA, Marr KA, Rolston KVI, Ramsey SD (2013) Antimicrobial prophylaxis and outpatient management of fever and neutropenia in adults treated for malignancy: American Society of Clinical Oncology clinical practice guideline. J Clin Oncol $31: 794-810$ 